\title{
Morphometric Study of Lumbar Vertebrae in Adult South African Subjects
}

\author{
Estudio Morfométrico de las Vértebras Lumbares en Sujetos Adultos de Sudáfrica
}

Azu, O. O."; Komolafe, O. A."**; Ofusori, D. A."*; Ajayi, S. A."; Naidu, E. C. S.* \& Abiodun, A. A..*

AZU, O. O.; KOMOLAFE, O. A.; OFUSORI, D. A.; AJAYI, S. A.; NAIDU, E. C. S. \& ABIODUN, A. A. Morphometric study of lumbar vertebrae in adult South African subjects. Int. J. Morphol., 34(4):1345-1351, 2016.

SUMMARY: Lumbar vertebral dimensions provide vital clinical information of immense diagnostic benefits to medical experts. The present study provides data for lumbar vertebral dimensions of a cohort of specimens of South African females and males. Measurements were obtained from lumbar vertebrae from the osteological collections in the Discipline of Clinical Anatomy, Nelson Mandela School of Medicine using a digital caliper. The antero-posterior body diameter (APD), interpedicular distance (IPD), midsagittal diameter (MSD) and pedicle length (PL) were measured while ratio of MSD to APD was calculated. Results showed gradual increase from L1 to L5 for mean APD and IPD, and a decrease for mean PL from L1 to L5. Mean MSD was observed to present a "U" curve pattern from L1 to L5, while MSD/APD ratio decreased from L2 downwards. We report that certain lumbar dimensions also showed significant correlation with age at distinct lumbar levels. The present data provides a baseline of lumbar vertebral morphology for the South African adult cohort and requires further investigations with larger cohort.

KEY WORDS: Lumbar vertebrae; Morphometry; Adults; South Africa.

\section{INTRODUCTION}

Dimensions of lumbar vertebrae hold key relevance in clinical diagnosis of lower backache (LBA) and lumbar spinal stenosis. The stenosis of the lumbar spinal canal is a condition in which the antero-posterior and lateral dimensions of the bony canal are less than normal for the relevant age and sex of the in-dividuals and one of the symptoms is low backache. LBA affects both occupational and non-occupational individuals whether in rural or urban setting with various degree of debilitation.

Lumbar spinal canal stenosis can be classified into developmental, degenerative and other types according to Kirkidy-Willis et al. (1974). Verbiest (1977) illustrated that the developmental stenosis is due to the properties of the neural arch, pedicles, laminae and articular processes in which the interpedicular distances are normal whereas lateral sagittal diameters are shortened due to thickened laminae and articular processes. The degenerative stenosis accompanied by osteoarthritis of the segmental spine is more marked opposite the intervertebral disc and pos-terior articular processes whereas anteroposterior and lateral diameters may be normal.
The combined stenosis shows overall nar-rowing of spinal canal or segmental narrowing, protrusion of disc or any combination of these, associated with more neurological symptoms than developmental and degenerative types.

Population specific variations are common in many body dimensions, hence it imperative to generate populations specific measurements for body dimensions that could hold clinical relevance. The present study therefore investigates the dimensions of lumbar vertebrae of South African females and males with a view to providing a baseline data and guide medical and diagnostic knowledge of experts (Clinicians, Orthopedic surgeons, and Radiologist) in their practice.

\section{MATERIAL AND METHOD}

Sample collection. Lumbar vertebrae from the osteological collections in the Discipline of Clinical Anatomy, Nelson R Mandela School of Medicine, University

\footnotetext{
* Discipline of Clinical Anatomy, Nelson R. Mandela School of Medicine, University of Kwazulu- Natal, Durban, South Africa.

** Department of Anatomy and Cell Biology, Faculty of Basic Medical Sciences, Obafemi, Awolowo University, Ile-Ife, Osun-State, Nigeria.
} 
of Kwazulu-Natal, Durban were used. The specimens represent the lumbar vertebrae of individuals who died during the apartheid era between the years 1908-1970 (over six decades). The study included collections archived of 107 individuals (103 males and 67 females) aged between 21 and 80 years. The total lumbar vertebrae measured was 298 with the following lumbar segments; $\mathrm{L} 1=46, \mathrm{~L} 2=82, \mathrm{~L} 3=92$, $\mathrm{L} 4=53, \mathrm{~L} 5=25$ (representing first to fifth lumbar vertebrae respectively. We excluded any vertebrae with obvious anatomical distortions emanation from obvious damage or pathology which would impair our assessments.

Ethical approval. Ethical approval was obtained from the UKZN Biomedical Research Ethics Committee (BREC) (Ethics number: BCA356/14).

Specimen measurement. All lumbar specimens (L1 to L5) were measured in millimeters $(\mathrm{mm})$ using digital caliper and were carried out in a supine placement of the vertebra in the axial plane by three different members of the team (to minimize inter-individual errors of reporting). The anteroposterior body diameter (APD) was measured as the anteroposterior distance of each vertebral body, while the interpedicular distance (IPD) was measured as the minimal distance between the medial surfaces of the pedicles on either side. The midsagittal diameter (MSD) was measured as the maximum anteroposterior distance of the spinal canal of each vertebra while the pedicle length (PL) were measured starting from the origin of the pedicle from the body to the superior articular facet on either side using the average. Ratio of midsagittal diameter to antero-posterior body diameter (MSD/APD) was calculated by dividing MSD by the APD (Fig. 1).

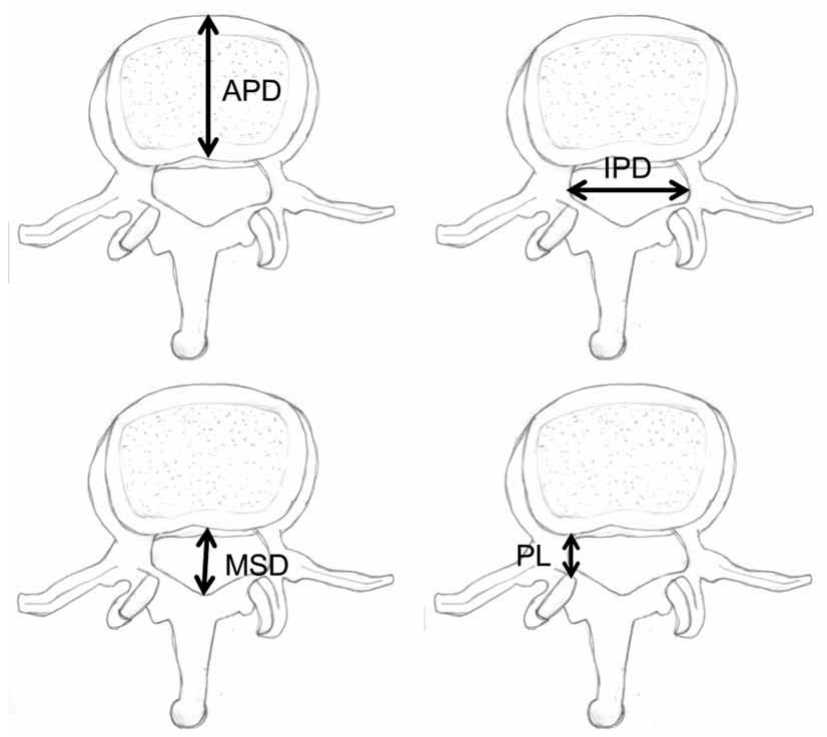

Fig. 1. Schematic illustration of measurement protocol.
Statistical analysis. Data were analyzed for descriptive statistics and represented as mean + standard deviation using GraphPad Prism 5 (Version 5.03, GraphPad Software, USA). Student's t-test was used to analyze for differences between gender while Pearson's correlation was used to check for association between age of subjects and the parameters recorded. Statistical significance was considered at $\mathrm{P}<0.05$.

\section{RESULTS}

The mean antero-posterior body diameter (APD) showed gradual increase from L1 to L5 $(\mathrm{L} 1=30.44 \mathrm{~mm}$; L2=31.78 mm; L3=32.67 mm; L4=34.05 mm; L5=35.55 $\mathrm{mm}$ ) with a range of $23.00-42.00 \mathrm{~mm}$ at $\mathrm{L} 1$ and $31.50-$ $46.60 \mathrm{~mm}$ at L5 (Fig. 2). This gradual increase was observed in both female and male specimens with a statistically significant difference between female and male APD of L1 and L3, but not at L2, L4 and L5 (Table I).

The mean interpedicular distance (IPD) showed steady increase from L1 to L5 (L1= $20.04 \mathrm{~mm}$; L2 $=20.79$ $\mathrm{mm} ; \mathrm{L} 3=21.40 \mathrm{~mm}$; L4=22.98 $\mathrm{mm}$; L5=24.01 mm) with a range of $14.50-26.40 \mathrm{~mm}$ at $\mathrm{L} 1$ and $15.70-30.90 \mathrm{~mm}$ at L5 (Fig. 3). This increase was observed in both females and males, and no significant difference in IPD was seen between the genders at any lumbar level (Table II).

The mean midsagittal diameter (MSD) showed a decrease from $\mathrm{L} 1$ to $\mathrm{L} 2(\mathrm{~L} 1=17.29 ; \mathrm{L} 2=16.29)$, and then a gradual increase from L3 to L5 (L3=16.62 mm; L4=17.53 $\mathrm{mm}$; L5=18.83 mm) (Fig. 4). This pattern was observed in both females and males, and no significant gender difference was noted at any lumbar level for MSD (Table III).

The mean pedicle length (PL) showed a gradual decrease from L1 to $\mathrm{L} 5(\mathrm{~L} 1=6.12 \mathrm{~mm} ; \mathrm{L} 2=5.57 \mathrm{~mm}$; $\mathrm{L} 3=4.50 \mathrm{~mm} ; \mathrm{L} 4=3.93 \mathrm{~mm} ; \mathrm{L} 5=3.19 \mathrm{~mm}$ ), with a range of $0.60-9.20 \mathrm{~mm}$ at L1 and 1.50-5.50 $\mathrm{mm}$ at L5 (Fig. 5). This decreasing pattern was consistent in males only, as there was in increase in PL of females at L3 relative to L2. Significant gender difference was thus observed at L3 (Table IV).

The mean MSD/APD ratio showed a gradual decrease from $\mathrm{L} 1$ to $\mathrm{L} 4$, and increased at $\mathrm{L} 5$ relative to $\mathrm{L} 4$, L3 and L2 (L1=0.59 mm; L2 $=0.52 \mathrm{~mm}$; L3 $=0.51 \mathrm{~mm}$; L4=0.51 mm; L5=0.53 mm) (Fig. 6). This pattern was followed in males only, as females showed an irregular pattern; a decrease at L2, then increase at L3, decrease at L4 and increase at L5. Significant gender difference was thus observed at L1 (Table V). 
APD was significantly correlated with age at L3 only, IPD at L1 only, SCD at L2 only, and SCD/APD ratio at L3 only. PL was not significantly correlated with age at any lumbar level. (Table VI)

Table I. Comparison of APD of lumbar vertebrae in female and male sample.

\begin{tabular}{|c|c|c|c|c|c|c|c|}
\hline \multirow{2}{*}{$\begin{array}{l}\text { Lumbar } \\
\text { Level }\end{array}$} & \multicolumn{4}{|c|}{ F emale } & \multicolumn{3}{|c|}{ Male } \\
\hline & Mean & $\mathrm{SD}$ & Range & Mean & SD & Range & t-test \\
\hline L1 & 27.98 & 2.66 & $23.00-32.70$ & 32.03 & 3.18 & $27.80-42.00$ & $4.48^{*}$ \\
\hline L2 & 31.04 & 2.10 & $26.70-37.70$ & 32.30 & 3.76 & $25.50-46.00$ & 1.61 \\
\hline L3 & 31.50 & 3.07 & $23.90-40.20$ & 33.16 & 2.86 & $27.70-42.30$ & $2.49^{*}$ \\
\hline L4 & 33.21 & 3.25 & $27.00-42.40$ & 34.65 & 3.90 & $27.40-43.00$ & 1.41 \\
\hline L5 & 36.08 & 4.40 & $31.50-46.60$ & 35.16 & 2.16 & $31.90-37.80$ & 0.68 \\
\hline
\end{tabular}

* $\mathrm{p}<0.05$ between female and male subjects at the lumbar level; all measurements in $\mathrm{mm}$.

Table II. Comparison of IPD of lumbar vertebrae in female and male in the sample.

\begin{tabular}{llllllll}
\hline Lumbar & \multicolumn{4}{c}{ Female } & \multicolumn{3}{c}{ Male } \\
Level & Mean & SD & Range & Mean & SD & Range & t-test \\
\hline L1 & 19.56 & 2.19 & $16.10-23.30$ & 20.34 & 2.63 & $14.50-26.40$ & 1.05 \\
L2 & 21.04 & 1.85 & $17.00-24.90$ & 20.61 & 1.91 & $16.60-26.40$ & 1.04 \\
L3 & 21.31 & 2.23 & $16.90-26.90$ & 21.44 & 1.81 & $17.00-26.10$ & 0.28 \\
L4 & 22.84 & 2.39 & $18.00-29.60$ & 23.08 & 2.41 & $16.70-27.50$ & 0.35 \\
L5 & 23.66 & 4.22 & $15.70-30.90$ & 24.26 & 3.13 & $17.30-27.80$ & 0.40 \\
\hline
\end{tabular}

Note: All measurements are in $\mathrm{mm}$.

Table III. Comparison of MSD of lumbar vertebrae in female and male sample.

\begin{tabular}{llllllll}
\hline Lumbar & \multicolumn{9}{c}{ Female } & \multicolumn{3}{c}{ Male } \\
\cline { 2 - 8 } Level & Mean & SD & Range & Mean & SD & Range & t-test \\
\hline L1 & 18.19 & 2.49 & $12.90-21.10$ & 17.53 & 2.86 & $11.00-22.60$ & 0.80 \\
L2 & 16.22 & 1.76 & $13.10-20.00$ & 16.34 & 1.46 & $13.10-19.00$ & 0.33 \\
L3 & 16.59 & 1.36 & $13.20-19.50$ & 16.63 & 1.83 & $13.00-21.00$ & 0.10 \\
L4 & 17.28 & 1.89 & $13.90-21.40$ & 17.71 & 2.36 & $14.70-23.70$ & 0.71 \\
L5 & 18.67 & 1.49 & $15.40-20.90$ & 18.94 & 2.76 & $12.70-23.20$ & 0.28 \\
\hline
\end{tabular}

Note: All measurements are in $\mathrm{mm}$.

Table IV. Comparison of PL of lumbar vertebrae in female and male samples.

\begin{tabular}{lllllllc}
\hline Lumbar & \multicolumn{5}{c}{ Female } & \multicolumn{5}{c}{ Male } \\
\cline { 2 - 8 } Level & Mean & SD & Range & Mean & SD & Range & t-test value \\
\hline L1 & 5.98 & 1.72 & $1.80-8.30$ & 6.21 & 2.05 & $0.60-9.20$ & 0.39 \\
L2 & 5.33 & 1.23 & $3.70-7.60$ & 5.73 & 1.34 & $3.40-8.80$ & 1.37 \\
L3 & 5.70 & 1.50 & $3.30-8.80$ & 4.76 & 1.32 & $2.50-7.90$ & $2.57^{*}$ \\
L4 & 3.77 & 1.24 & $1.90-6.70$ & 4.04 & 1.28 & $1.70-6.80$ & 0.76 \\
L5 & 3.21 & 0.93 & $2.00-5.50$ & 3.17 & 0.87 & $1.50-4.40$ & 0.10 \\
\hline
\end{tabular}

$* \mathrm{p}<0.05$ between female and male subjects at the lumbar level; measurements are in $\mathrm{mm}$.

Table V. Comparison of MSD/APD ratio of lumbar vertebrae in female and male sample.

\begin{tabular}{llllllll}
\hline Lumbar & \multicolumn{4}{c}{ Female } & \multicolumn{3}{c}{ Male } \\
\cline { 2 - 8 } Level & Mean & SD & Range & Mean & SD & Range & t-test \\
\hline L1 & 0.65 & 0.09 & $0.47-0.77$ & 0.55 & 0.09 & $0.34-0.74$ & $3.72^{*}$ \\
L2 & 0.52 & 0.07 & $0.42-0.73$ & 0.51 & 0.07 & $0.33-0.68$ & 0.69 \\
L3 & 0.53 & 0.07 & $0.39-0.67$ & 0.51 & 0.07 & $0.37-0.65$ & 1.67 \\
L4 & 0.52 & 0.05 & $0.39-0.63$ & 0.51 & 0.10 & $0.19-0.72$ & 0.65 \\
L5 & 0.53 & 0.06 & $0.41-0.59$ & 0.54 & 0.09 & $0.37-0.67$ & 0.57 \\
\hline
\end{tabular}

$* \mathrm{p}<0.05$ between female and male subjects at the lumbar level; measurements are in $\mathrm{mm}$. 


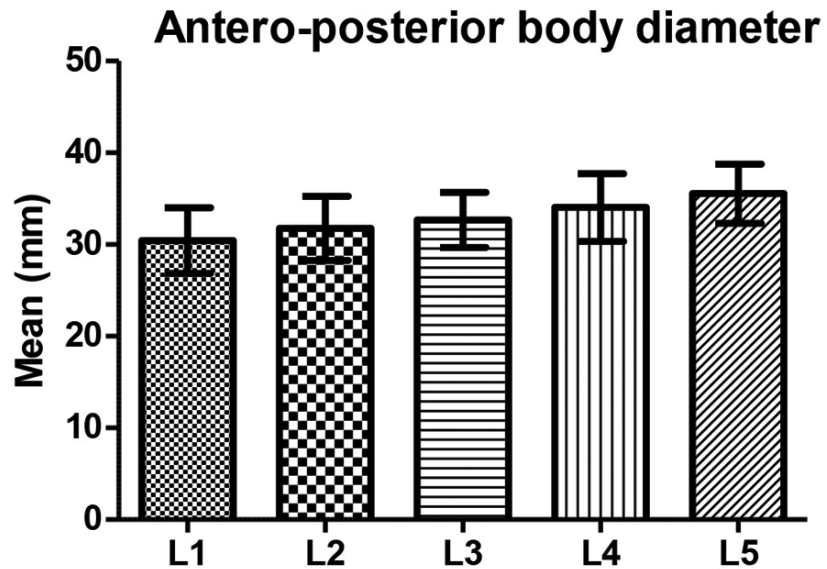

Fig. 2. Bar chart showing antero-posterior body diameter (APD) in sample.



Fig. 3. Bar chart showing lumbar interpedicular distance (IPD) in sample.

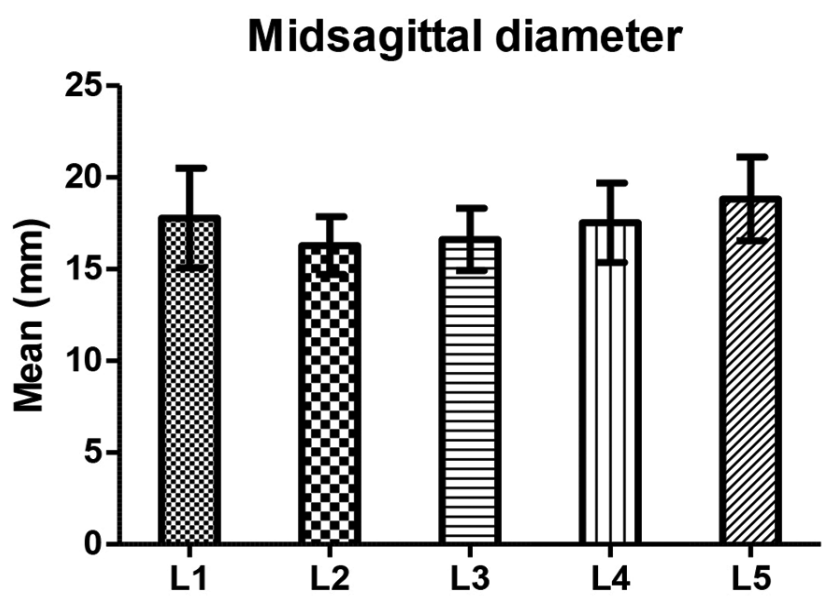

Fig. 4. Bar chart showing lumbar midsagittal diameter (MSD) in sample.
Pedical length

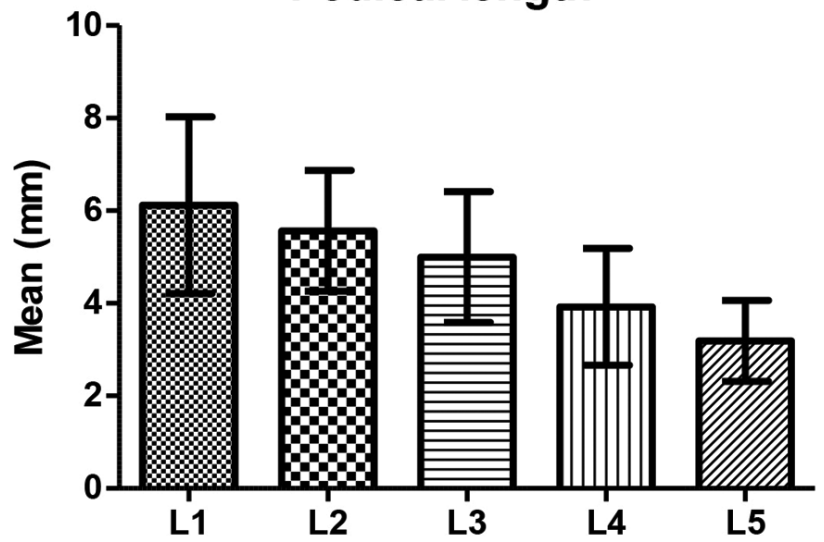

Fig. 5. Bar chart showing lumbar pedicle length (PL) in the sample.

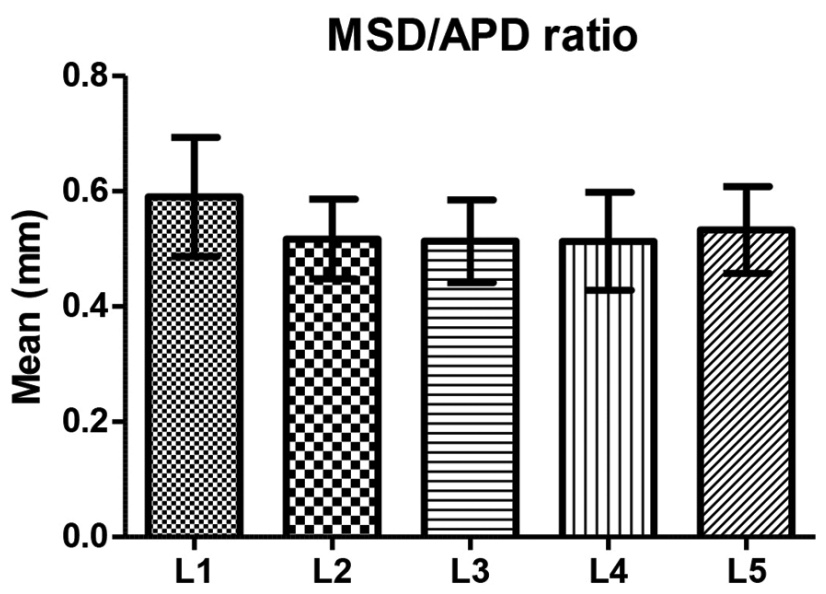

Fig. 6. Bar chart showing lumbar MSD/APD ratio in sample.

\section{DISCUSSION}

Low back ache ranks amongst the top frequently observed symptom in the musculoskeletal system of humans (Atta-Alla el et al., 2014). While research indicates that the prevalence of LBA among Africans may compare favorably with data from developed countries, there are increasing worries on the rising burden of LBA on the wellbeing of patients within the continent (Louw et al., 2007). More so, assessing the size of the lumbar vertebral canal serves as an essential diagnostic tool for low back ache (El-Rakhawy et al., 2010). The alignment of spinal canal of lumbar vertebrae is determined by structures that surround the successive spinal foramina and any pathological changes in canal diameter could be related to LBA (El-Rakhawy et al.). Hence, 
AZU, O. O.; KOMOLAFE, O. A.; OFUSORI, D. A.; AJAYI, S. A.; NAIDU, E. C. S. \& ABIODUN, A. A. Morphometric study of lumbar vertebrae in adult South African subjects. Int. J. Morphol., 34(4):1345-1351, 2016.

Table VI. Correlation of Age with lumbar measurements.

\begin{tabular}{lccccc}
\hline $\begin{array}{l}\text { Lumbar } \\
\text { Segment }\end{array}$ & Age \& APD & Age \& IPD & Age \& SCD & Age \& PL & $\begin{array}{c}\text { Age \& } \\
\text { SCD/APD ratio }\end{array}$ \\
\hline L1 & -0.01 & $0.35^{*}$ & -0.03 & 0.22 & -0.03 \\
L2 & 0.17 & 0.10 & $0.23^{*}$ & 0.12 & -0.01 \\
L3 & $0.22^{*}$ & 0.10 & -0.14 & -0.06 & $-0.23^{*}$ \\
L4 & 0.19 & 0.13 & 0.16 & 0.17 & 0.02 \\
L5 & 0.18 & 0.01 & 0.12 & -0.15 & 0.02 \\
\hline
\end{tabular}

Pearson's correlation coefficient $(\mathrm{r}) * \mathrm{P}<0.05$; all measurements are in $\mathrm{mm}$

the morphology of the lumbar vertebrae shows regional curvatures on the sagittal plane, particularly necessary for impact absorption, reducing longitudinal stiffness as well as strengthening muscular activities (Atta-Alla el et al.).

The gradual anatomical narrowing of the vertebral canal or intervertebral foramina of the lumbar vertebrae is called lumbar spinal stenosis resulting to compression of the spinal cord that traverses the centrally located vertebral canal or lumbosacral spinal nerve roots that traverses the laterally located intervertebral foramina. Clinical symptoms of lumbar spinal stenosis include low back ache, bilateral lower limbs pain, paresthesia amongst other neurologic anomalies (Storm et al., 2002; Bajwa et al., 2013). The data presented in this study hence provides relevant clinical and morphological information on lumbar vertebral arrangement within the cohort sample.

Populations specific variations in dimensions of body segments necessitates continuous data gathering of lumbar dimensions in various population groups. In addition, whilst most studies have utilized measurements from different imaging techniques, including radiographs (Eisenstein, 1977; Amonoo-Kuofi, 1982; Nirvan et al., 2005; El-Rakhawy et al.; Atta-Alla el et al.), CT scans (Zhou et al., 2000; Midia \& Miabi, 2007; Aly \& Amin, 2013) as well as MRI images (Jeong et al., 2006; GocmenMas et al., 2010), only few studies have utilized direct measurements from the lumbar vertebrae (Eisenstein; Amonoo-Kuofi, 1985; El-Rakhawy et al.; Bajwa et al.). It is argued that direct measurements may give more accurate and reproducible results (Amonoo-Kuofi), hence it is necessary to have more data from direct measurements to compare with those from imaging techniques with a view to providing a reference standard for lumbar dimensions within the population group (South Africa).

Our study reports that mean APD gradually increases from L1-L5 in concordance with the work of Gocmen-Mas et al., from MRI studies, thus suggesting similarity in trend of lumbar vertebral body sizes from both direct and imaging measurements. This increase may be due to more weight bearing capabilities of the lower lumbar vertebrae. Eisenstein had previously seen such gradual decreasing pattern from L1-L5 in Sotho Negroid, Zulu Negroid and Caucasoid females and Sotho Negroid males of South Africa. However, such pattern was not consistent in Negroid and Caucasoid males, as there was a decrease mean values of $\mathrm{L} 5$ relative to L4. Significant gender difference was observed at L1 and L3 only. Gocmen-Mas et al. found no such gender differences in body diameter from MRI images.

This study also found a gradual increase in IPD from L1-L5. This pattern is consistent with that obtained from radiographic images of a Nigerian population by AmonooKuofi. However, mean IPD for females and males were lower in the present study as compared to values from AmonooKuofi were mean IPD was $21.3 \mathrm{~mm}$ at L1 and $28.4 \mathrm{~mm}$ at L5 for females, and $22.6 \mathrm{~mm}$ at L1 and $28.7 \mathrm{~mm}$ at L5 for males. The present data are quite comparable to those obtained by Eisenstein, who recorded mean IPD values for both Sotho and Zulu Negroid females of South Africa as 20 $\mathrm{mm}$ at L1 and $24 \mathrm{~mm}$ at L5. Eisenstein observed that while both Sotho and Zulu Negroid males had mean IPD of 21 $\mathrm{mm}$ at L1, Sotho males had mean IPD of $25 \mathrm{~mm}$ at L5, and Zulu males had $26 \mathrm{~mm}$ at L5.

This study also showed that mean MSD developed a "U" curve pattern, as values decrease at $\mathrm{L} 2$ before continuing a subsequent increase in mean MSD towards L5. This " $U$ " curve pattern of MSD was also reported by Eisenstein in Sotho and Zulu Negroid males and females as well as Caucasoid females and males of South African origin. In comparison of IPD values from the present study and that of Amonoo-Kuofi on a Nigerian population, mean MSD values for females and males were higher in the present report (South African Lumbar vertebra samples). Amonoo-Kuofi however observed that mean MSD from vertebrae specimens in a Nigerian population were $15.6 \mathrm{~mm}$ at L1 and $14.6 \mathrm{~mm}$ at L5 for females, while for males, mean MSD were 16.6 $\mathrm{mm}$ at $\mathrm{L} 1$ and $16.0 \mathrm{~mm}$ at L5.

IPD and MSD parameters have been used to diagnose lumbar stenosis, though MSD is more used in many cases (Eisenstein; Storm et al.). Eisenstein suggested average lower limits of $18 \mathrm{~mm}$ for APD as the normal, beyond which the 
lumbar is considered stenotic for this dimension. In line with this, stenotic cases observed in the present study are as follows: L1 - 3 females, 5 males; L2 - 2 females, 5 males; L3 - 2 females, 1 male; L4 - 0 female, 1 male; L5 - 1 female, 1 male. Overall, 7 females and 13 males showed stenosis in any lumbar vertebrae for this dimension. On the other hand, normal MSD is defined as greater than $12 \mathrm{~mm}$, relative stenosis occurs between 10-12 mm and absolute stenosis at less than $10 \mathrm{~mm}$ (Storm et al.). The study observed only two cases of stenosis, both of which at L1 for this dimension.

The current study showed a gradual decrease in mean PL from L1-L5. This may be linked to the increasing size of lumbar body from the upper to the lower lumbar vertebrae. This observation however, contrasts with Atta-Alla el et al. These authors, observed an increase in pedicle length from L1-L5, which they measured as horizontal pedicle diameter from radiographic images. MSD/APD ratio was observed to decrease from upper to lower lumbar vertebrae in the present study. This pattern is also observed by Amono-Kuofi and Bajwa et al., on lumbar vertebrae specimens in a Nigerian and an American population respectively. The
MSD/APD ratio, also called the Torg ratio has been used been used for diagnostic parameter for predicting cervical spinal stenosis, and has being suggested that it will also be of relevance in radiological diagnosis of lumbar spinal stenosis (Bajwa et al.). Also, this study has demonstrated significant correlation between certain lumbar dimensions at distinct levels and age of subjects. This information may be relevant to anthropologists interested in understanding association between age and skeletal lumbar remains.

In conclusion, the dimensions and parameters obtained in this study forms baseline normative data for the South African adult population. We believe that in the absence of any known pathologies (as excluded in our sampling/records) of the sample, this investigation warrants further exploration with higher sample size and possibly inclusive of other regions in other to get a population-specific norm. Nonetheless, it gives an understanding of the morphological relevance of the lumbar vertebrae to clinical diagnosis of LBA for clinicians and could as well trigger forensic relevance due to population specific variations in body dimensions.

AZU, O. O.; KOMOLAFE, O. A.; OFUSORI, D. A.; AJAYI, S. A.; NAIDU, E. C. S. \& ABIODUN, A. A. Estudio morfométrico de las vértebras lumbares en sujetos adultos de Sudáfrica. Int. J. Morphol., 34(4):1345-1351, 2016.

RESUMEN: Las dimensiones lumbares vertebrales proporcionan información vital en la clínica para alcanzar un diagnóstico correcto. El presente estudio proporciona datos de las dimensiones vertebrales lumbares en una cohorte de hombres y mujeres de Sudáfrica. Las mediciones de las vértebras lumbares se obtuvieron de colecciones osteológicas correspondientes a la Cátedra de Anatomía Clínica, de la Escuela de Medicina Nelson Mandela. Se utilizó un calibrador digital. Se midieron el diámetro antero-posterior del cuerpo vertebral (DPA), la distancia interpedicular (DIP), el diámetro sagital mediano (DSM) y la longitud del pedículo (LP); y se calculó la relación de DSM con DPA. Los resultados mostraron un aumento gradual de L1 a L5 para la mediana de DPA y DIP, y una disminución de la media de LP de L1 a L5. La media de DSM presentó un patrón de curva en "U" de L1 a L5, mientras que el índice DSM / DPA disminuyó de L2 hacia inferior. Ciertas dimensiones lumbares también mostraron una correlación significativa con la edad en los distintos niveles lumbares. El presente estudio proporciona datos acerca de la morfología vertebral lumbar para una cohorte de adultos de Sudáfrica, y consideramos que se requieren de más investigaciones con una cohorte más amplia.

PALABRAS CLAVE: Vertebras lumbares; Morfometría; Adultos; Sudáfrica.

\section{REFERENCES}

Aly, T. \& Amin, O. Geometrical dimensions and morphological study of the lumbar spinal canal in the normal Egyptian population. Orthopedics, 36(2):e229-34, 2013.

Amonoo-Kuofi, H. S. Maximum and minimum lumbar interpedicular distances in normal adult Nigerians. J. Anat., 135(Pt. 2):225-33, 1982.

Amonoo-Kuofi, H. S. The sagittal diameter of the lumbar vertebral canal in normal adult Nigerians. J. Anat., 140(Pt. 1):69$78,1985$.

Atta-Alla el, S. S.; Saab, I. M.; El Shishtawy, M. \& Hassan, K. H.
Morphometric study of the lumbosacral spine and some of its related angles in Lebanese adult females. Ital. J. Anat. Embryol., 119(2):92-105, 2014.

Bajwa, N. S.; Toy, J. O. \& Ahn, N. U. Application of a correlation between the lumbar Torg ratio and the area of the spinal canal to predict lumbar stenosis: a study of 420 postmortem subjects. J. Orthop. Traumatol., 14(3):207-12, 2013.

Eisenstein, S. The morphometry and pathological anatomy of the lumbar spine in South African negroes and caucasoids with specific reference to spinal stenosis. J. Bone Joint Surg Br., 59(2):173-80, 1977. 
El-Rakhawy, M.; El-Rahman El-Shahat, A.; Labib, I. \& Abdulaziz, E. Lumbar vertebral canal stenosis: concept of morphometric and radiometric study of the human lumbar vertebral canal. Anatomy, 4:51-62, 2010.

Gocmen-Mas, N.; Karabekir, H.; Ertekin, T.; Edizer, M.; Canan, Y. \& Izzet Duyar, I. Evaluation of lumbar vertebral body and disc: A stereological morphometric study. Int. J. Morphol., 28(3):841-7, 2010.

Jeong, S. T.; Song, H. R.; Keny, S. M.; Telang, S. S.; Suh, S. W. \& Hong, S. J. MRI study of the lumbar spine in achondroplasia. A morphometric analysis for the evaluation of stenosis of the canal. J. Bone Joint Surg. Br., 88(9):1192-6, 2006.

Kirkaldy-Willis, W. H.; Paine, K. W.; Cauchiox, J. \& McIvor, G. Lumbar spinal stenosis. Clin. Orthop. Relat. Res., (99):30-50, 1974.

Louw, Q. A.; Morris, L. D. \& Grimmer-Somers, K. The prevalence of low back pain in Africa: a systematic review. B. M. C. Musculoskelet. Disord., 8:105, 2007.

Midia, M. \& Miabi, Z. Quantitative size assessment of the lumbar spinal canal by computed tomography. Acta Med. Iran., 45(5):377-82, 2007.

Nirvan, A. B.; Pensi, C. A.; Patel, J. P.; Shah, G. V. \& Dave, R. V. A study of inter-pedicular distances of the lumbar vertebrae measured in plain antero-posterior radiograph in Gujaratis. $J$. Anat. Soc. India, 54(2):58-61, 2005.

Storm, P. B.; Chou, D. \& Tamargo, R. J. Lumbar spinal stenosis, cauda equina syndrome, and multiple lumbosacral radiculopathies. Phys. Med. Rehabil. Clin. N. Am., 13(3):71333, 2002.

Verbiest, H. Results of surgical treatment of idiopathic developmental stenosis of the lumbar vertebral canal. A review of twenty-seven years' experience. J. Bone Joint Surg. Br., 59(2):181-8, 1977.

Zhou, S. H.; McCarthy, I. D.; McGregor, A. H.; Coombs, R. R. \& Hughes, S. P. Geometrical dimensions of the lower lumbar vertebrae--analysis of data from digitised CT images. Eur. Spine J., 9(3):242-8, 2000.

\author{
Correspondence to: \\ Dr. O.O. Azu \\ School of Laboratory Medicine and Medical Sciences \\ Department of Clinical Anatomy \\ Nelson R. Mandela School of Medicine \\ College of Health Sciences \\ University of KwaZulu- Natal \\ Private Bag X54001 \\ Durban 4000 \\ SOUTH AFRICA
}

E-mail: azu@ukzn.ac.za

Received: 18-11-2016

Accepted: 07-09-2016 